\title{
Optimal Power Flow Approach for Cognitive and Reliable Operation of Distributed Generation as Smart Grid
}

\author{
Vilas S. Bugade*, Pradeep K. Katti \\ Dr. Babasaheb Ambedkar Technological University, Lonere, India \\ Email: * punamvilas12@gmail.com
}

How to cite this paper: Bugade, V.S. and Katti, P.K. (2017) Optimal Power Flow Approach for Cognitive and Reliable Operation of Distributed Generation as Smart Grid. Smart Grid and Renewable Energy, 8, 87-98.

https://doi.org/10.4236/sgre.2017.83006

Received: February 6, 2017

Accepted: March 24, 2017

Published: March 28, 2017

Copyright ( 92017 by authors and Scientific Research Publishing Inc. This work is licensed under the Creative Commons Attribution International License (CC BY 4.0).

http://creativecommons.org/licenses/by/4.0/

\begin{abstract}
Smart grid expertise emphasises on the compound connections of the electricity to the grid, along with computing, control and communication interface. It will bring together in future smart infrastructure for power system. Investigating these complex dynamic interactions is crucial for the efficiency and robustness of the emerging smart grid. In particular, it is one of the key elements for smart-grids to establish the dynamics among sources of grid. This paper proposes the vital operation of renewable energy sources (RES) like Solar Photovoltaic (PV), wind energy with existing grid of a. c. network of power system in view of cognitive reliable operation of RES as add-on source of power. The research presents sequence of operation of these sources by optimal power flow based on power flow chart for demand side management as a smart grid of power system. The system fulfils realistic operation for power system, based on fundamentals of power system, therefore a necessary research topology is developed, for well-regarded schemes of RES for setting up a pilot model so that demand side load should not be hampered and same is verified for linear and non-linear loads of electrical networks.
\end{abstract}

\section{Keywords}

Smart Grid, Micro Grid, RES, Distributed Generation

\section{Introduction}

Renewable energy resources (RES), such as wind and solar PV, are considered highly auspicious in the face of emergent anxieties for the surroundings, energy conservation, and sustainable development. As seasonal variability are inherent to both wind and solar PV resources. Conventionally, the indecision of an independent solar PV panel or wind turbine installation is managed using a storage 
system. However, this results in an increased overall cost of the output energy, and therefore limits the benefits of using renewable energy. A hybrid system uses two renewable energy sources as solar PV and wind energy, thus improving the system efficiency, power reliability and reducing the energy storage obligation. However, accumulating integrally stochastic power sources such as wind and solar PV to achieve reliable electricity supply is a non-inconsequential problem. In the modern power system planning, cohort is dispatched to tie the load. Power system frequency directive, voltage mechanism and other key ancillary services are provided by controlling large-scale generators, transformers and other bulk-power devices [1].

Smart grid skills and facilities are being developed from an assortment of perceptions. Whereas the innovative smart grid infrastructure is expected to increase the efficiency and reliability of grid operations, the increased complexity of the new system has to be addressed. Obtaining huge volumes of statistics from loads of advanced smart topologies self does not indicate that a grid becomes intelligent. Unlike traditional power grid systems, the future grid will invariably feature rapid integration of alternative forms of energy generation; thus, power flows bi-directionally as shown in Figure 1.

However it has been discussed in the literature for eras, the perception of monitoring end-use loads to match generation has only recently become gorgeous to scholars due, partly, to improvements in work out and communication technologies, but similarly due to tenacious anxieties regarding the integration of alternating and variable RES to the grid. The Central Energy Regulatory Commission (CERC) of India in recent times issued a report on the benefits of Demand Response (DR), the extensive concept under which this awareness falls, showing a possible $12 \%$ reduction of the forecasted peak demand for 2017 compared to the case without DR. This report, however, does not take into version sovereign, distributed device approaches. Though, study by imitations and a mi-

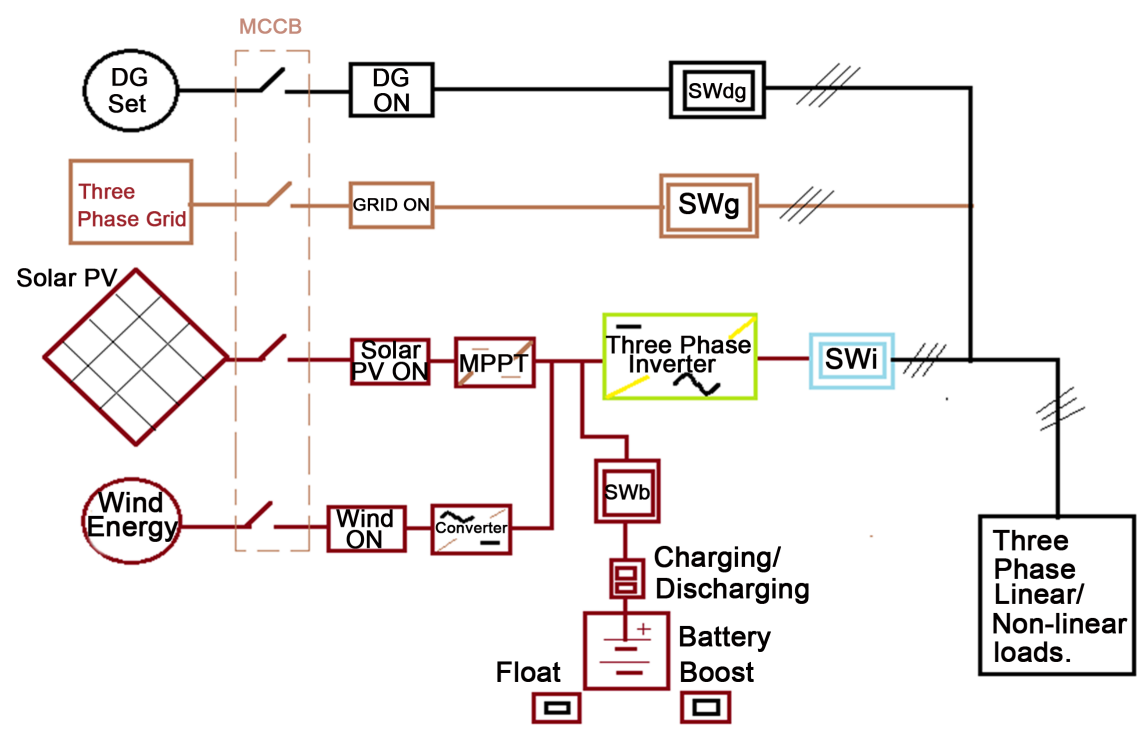

Figure 1. Block diagram of three phase SMARTGRID system with RES. 
nor experimental program has established the benefits of using hundreds or even thousands of small controllable loads to balance the cumulative load and generation.

In recent times, there has been an enlarged interest in using thermostaticallycontrolled loads (TCLs) to leverage demand response [2]. Their capability to be swapped ON/OFF deprived of substantial impact to their end-use function makes them attractive for providing a short-time measure comeback to adverse frequency variations initiated by intermittent generation sources [3].

In this paper, a demand side management approach is anticipated by Heuristic Optimization method for smart grid [4]. The strategy is based on load shifting technique, which can handle a large number of devices of several types [5]. A heuristic based evolutionary flowchart that can easily adapt its heuristics has been developed for solving the problem in section 1 . Section 2 briefly describes the optimal power flow technique for future smart grid. The simulation for power flow analysis were carried out on a smart grid which has different types of generation sources with a variety of loads in section 3 and section 4 gives hardware results of each source and combination with existing grid. Section 5 concludes the paper.

\section{Evolutionary Flowchart Topographies for a Suitable Demand Side Management Technique for Future Smart Grid}

This section gives conceptual demand side management with relative generation status of the system as shown in Figure 1.

The block diagram consists of solar PV, wind energy, battery, Diesel generator and exiting grid whose power rating is specified in simulation model. The three phase inverter is for converting unconditioned d. c. power in to conditioned a. c. power of solar PV, wind energy and battery source. At the outset the power is delivered to three phase load through point of common coupling (PCC) [6].

Eventually each generation is represented as a source and at PCC the gathered parameters gives intimation for operating the switches at node of generating sources as Switch (SW) in auto mode. The subscript for each SW represents the generating source in Figure 2.

The sequential power flow chart in the form of exchange of power by RES to load is given in the flow chart. It represents the operation of SMARTGRID as RES-GRID-Battery-DG or RES-Battery-GRID-DG. The power flow is based on the generation priority of the source and its availability Figure 3 i.e. the fulfillment of load. An approach is to make system convenient with significant use of generation source by either way [7].

\section{Optimal Power Flow Strategy for Smart Grid}

The demand side is basically have two commands in the way the load connected and disconnected. For controlling the generation power dispatching flow at PCC these parameters need to be considered with real time. From the data available of 


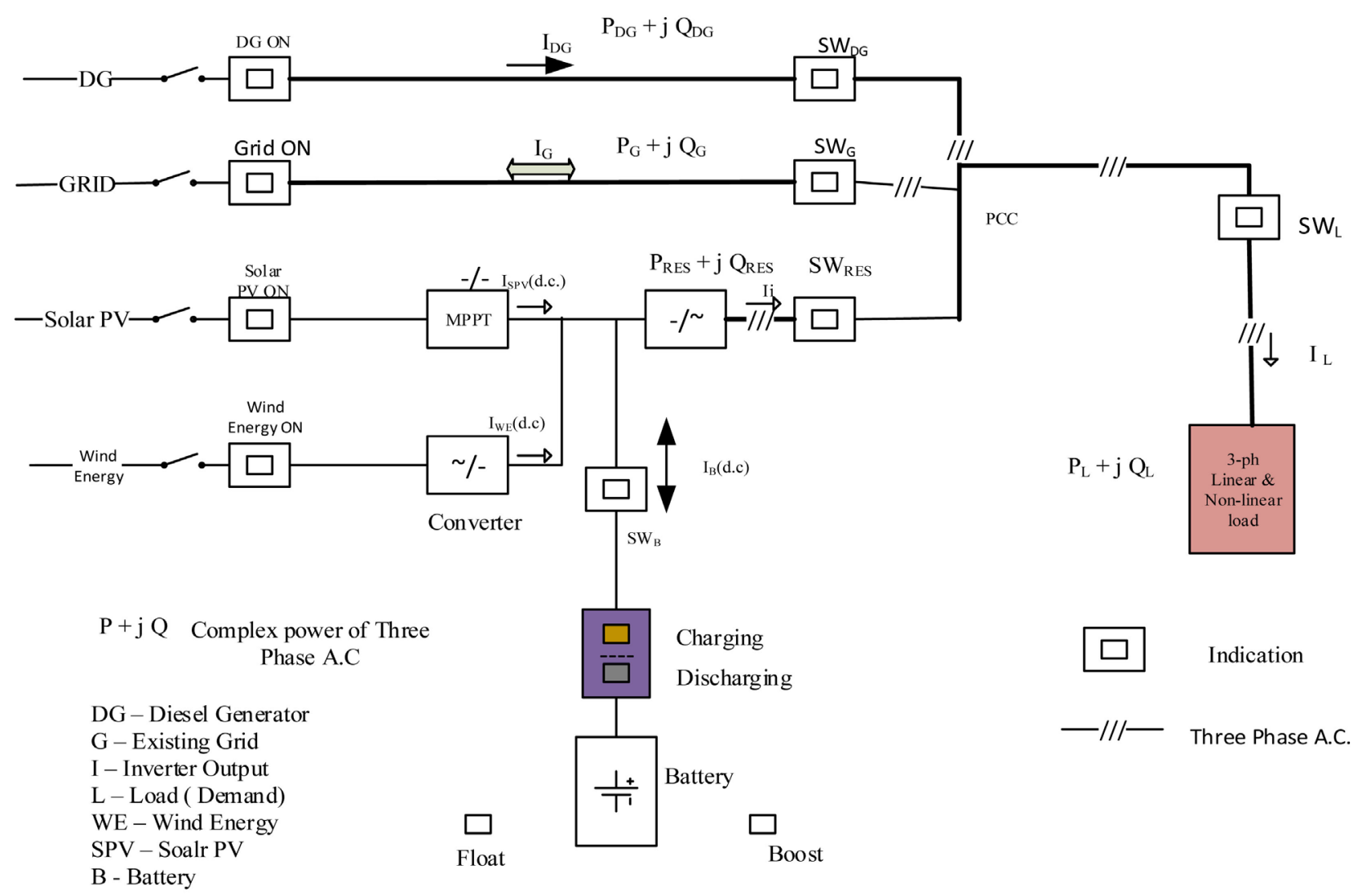

Figure 2. Power flow diagram of SMARTGRID with RES.

the connected load in the system, the demand to be supplied or otherwise will be known from (i) the magnitude of load connected (demanded) (ii) the magnitude of load disconnected ( Switched OFF ) where in a balance is required maintained.

The proposed demand side strategy schedules the switching moments of each source of power for the system in a way that brings the load consumption as the objective of system. Proposed load fulfillment is mathematically formulated based on the power flow analysis as presented in flowchart shown in Figure 3,

$$
\sum_{t=1}^{N} P_{D}(t)=\sum_{t=1}^{N} P_{L}(t)-\sum_{t=1}^{N} P_{L}(t) \text { disconnected }
$$

where $P_{L}(t)$ is actual consumption at time " $t$ " sec.

The $P_{i}(t)$ the inverter output three phase a.c. power as shown in Figure 2 then, if

$$
\begin{aligned}
& \sum_{t=1}^{N} P_{D}(t)=\sum_{t=1}^{N} P_{i}(t) \\
& \sum_{t=1}^{N} P_{D}(t)<\sum_{t=1}^{N} P_{i}(t)
\end{aligned}
$$

For the Equations (2) and (3) the $S W_{g}, S W_{b}$ and $S W_{d g}$ are at OFF position of Figure 2 and at Equation (3) the $S W_{g}$ acts like bidirectional switch which will-ve sign returns the power to grid as Equation (4), the same will be displayed and reflected in power returns $P_{i r}(t)$ as, 


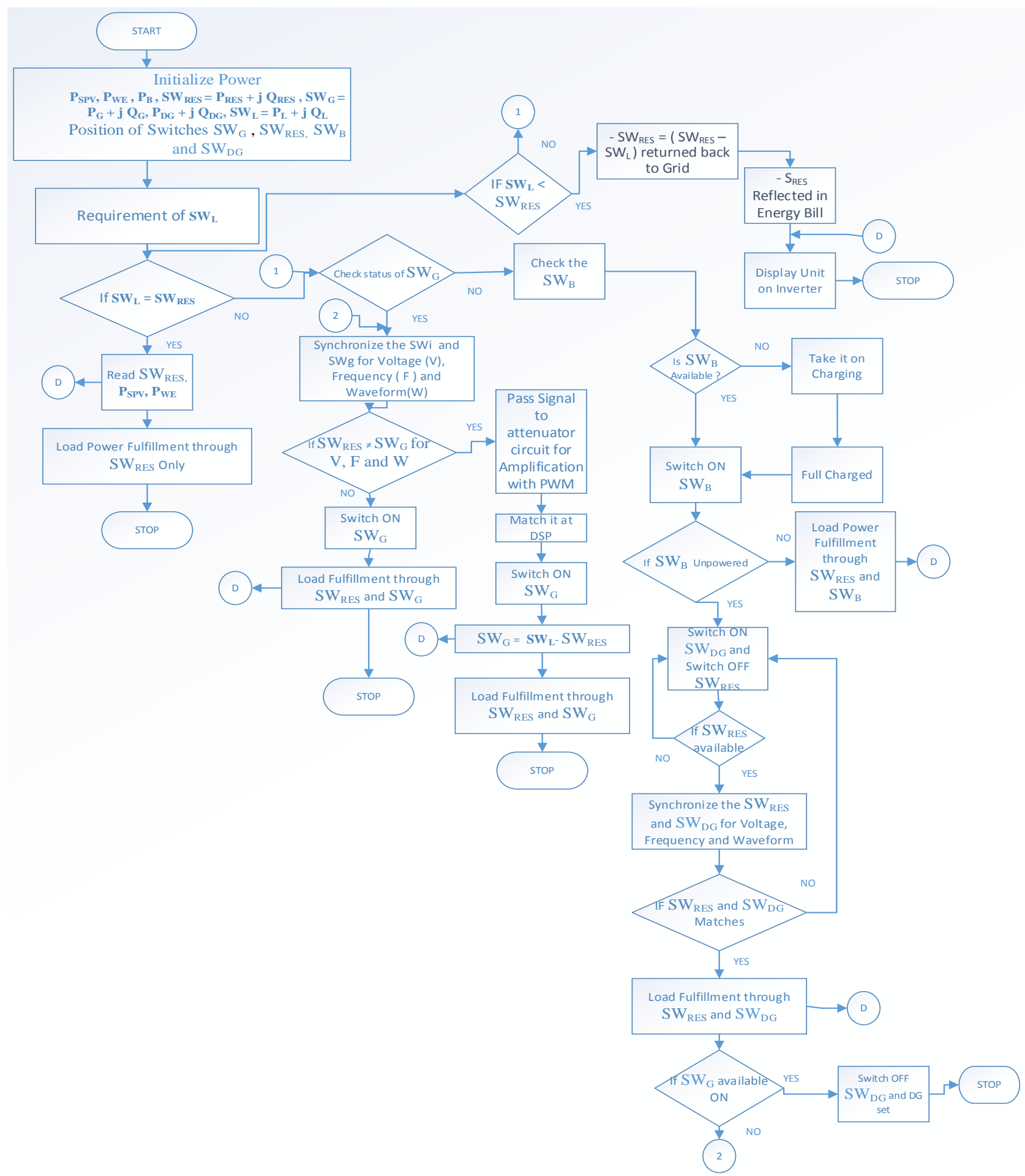

Figure 3. Power flow chart of SMARTGRID.

$$
-\sum_{t=1}^{N} P_{i r}(t)=\sum_{t=1}^{N} P_{i}(t)-\sum_{t=1}^{N} P_{D}(t)
$$

If,

$$
\sum_{t=1}^{N} P_{D}(t)>\sum_{t=1}^{N} P_{i}(t)
$$


Then

$$
\sum_{t=1}^{N} P_{D}(t)=\sum_{t=1}^{N} P_{i}(t)+\sum_{t=1}^{N} P_{G}(t)
$$

For the Equation (6) the $S W_{b}$ and $S W_{d g}$ are at OFF position of Figure 2, Where $P_{G}(t)$ is the three phase grid power from Figure 2 and the power taken from grid will be,

$$
\sum_{t=1}^{N} P_{G}(t)=\sum_{t=1}^{N} P_{D}(t)-\sum_{t=1}^{N} P_{i}(t)
$$

Hence the power flow analysis will be achieved from above but the limitation is that all the time $P_{i}(t)$ may or may not be available and $15 \%$ of rated capacity of RES needs to reserve the power. If $P_{G}(t)$ is not available then in Equation (6) and (7) the $P_{G}(t)$ will be replaced by $P_{d g}(t)$ of diesel generator for this $S W_{g}$ and $S W_{b}$ is in OFF position of Figure 2. Also if $P_{G}(t)$ and $P_{i}(t)$ both are unpowered then load fulfillment through $P_{d g}$ for this $S W_{g}, S W_{i}$ and $S W_{b}$ is in OFF position of Figure 2.

The source battery in the Figure 2 is used as standby power source or as a back up to the network as well as conditioned power source for power drive and control circuit. Charging of battery is through RES only and during discharging the total d.c. input power to the $P_{i}(t)$ becomes $P_{s p v}+P_{w e}+P_{b}$.

To create an optimal power flow for equation (6) and equation (7) from first order transfer function, which eliminates the steady state error at the output for active $\left(P_{i}\right)$ and reactive $\left(Q_{i}\right)$ power of the inverter [8].

$$
\begin{gathered}
\frac{\mathrm{d} P_{i}}{\mathrm{~d} t}=\frac{P_{\text {max }}}{\tau_{p}}\left(U_{p}-\frac{P_{i}}{P_{\text {max }}}\right) \\
\frac{\mathrm{d} Q_{i}}{\mathrm{~d} t}=\frac{Q_{\max }}{\tau_{q}}\left(U_{q}-\frac{Q_{i}}{Q_{\max }}\right)
\end{gathered}
$$

where $U_{p}, U_{q}$ is output signal from inverter respectively, $P_{\max }, Q_{\max } \max -$ imum output of inverter, $\tau_{p}, \tau_{q}$ time constant w.r.t. active and reactive power respectively in (8), (9).

Then for battery as storage device [8] [9],

$$
\begin{gathered}
\frac{\mathrm{d} P_{b}}{\mathrm{~d} t}=\frac{P_{\max b}}{\tau_{b}}\left(U_{b}-\frac{P_{b}}{P_{\max }}\right) \\
\frac{d_{s o c}}{\mathrm{~d} t}=b \cdot P_{b}
\end{gathered}
$$

$U_{b}$ is the signal for power that the battery generates $P_{\max b}$ maximum output power of battery.

Based on this optimal flow power the problem formulation can be created to know power requirement at PCC on $P_{D}(t)$ and $P_{G}(t)$ as follows [8]:

Using Kirchhoff voltage law in Figure 4, the voltage of the terminal can be expressed as, 


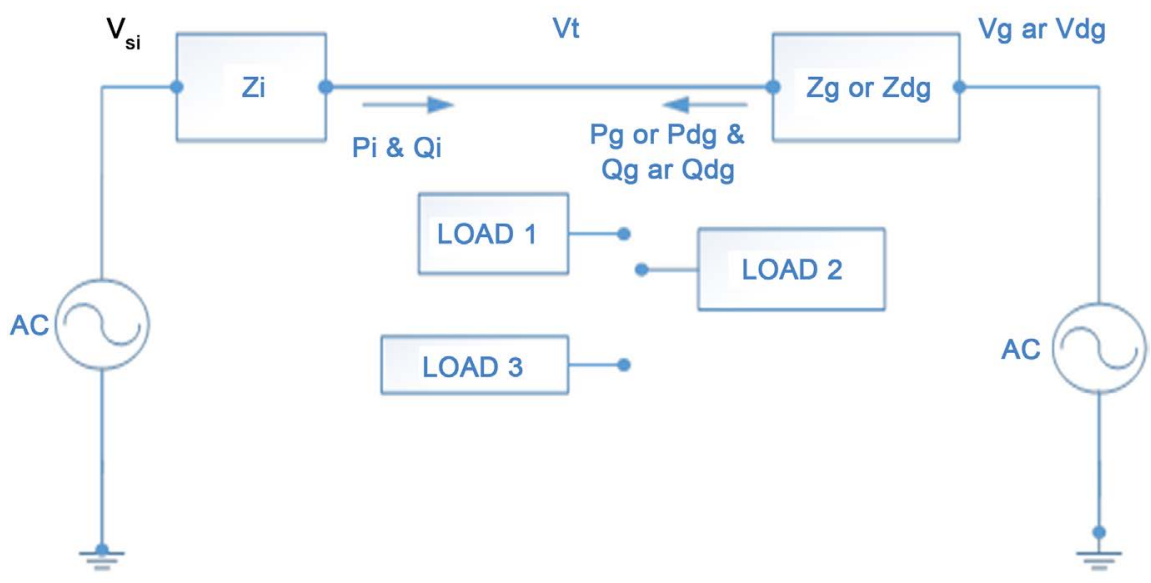

Figure 4. Terminal bus at PCC for voltage and frequency constraints.

$$
V_{t}=V_{s i}-\frac{\left|Z_{i}\right| S_{i}}{V_{S 1}}=V_{g} \text { or } V_{d g}-\frac{\mid Z_{g} \text { or } Z_{d g} \mid S_{g} \text { or } S_{d g}}{V_{g} \text { or } V_{d g}}
$$

In which $V_{s i}$ and $V_{g}$ or $V_{d g}$ is the output voltage at inverter and grid or DG, $Z_{i}$ and $Z_{g}$ or $Z_{d g}$ impedances of lines of inverter and grid or DG. The output voltage at respective nodes depends on frequency and current, therefore difference between on $P_{L}(t)$ Connected and $P(t)$ Generated could cause the variation in the frequency [9] [10],

$$
\frac{\mathrm{d} \omega}{\mathrm{d} t}=\lambda\left(P_{\text {Generated }}-P_{D}\right)+\left(\omega_{\max }-\alpha P-\omega\right)
$$

For islanded distributed generation it is important to maintain the frequency and voltage regulation. The aim of control frequency and voltage a proper effective function could be defined as [8]:

$$
J=\int_{t_{0}}^{t_{f}}\left(\xi_{\omega}\left|\omega-\omega_{r e f}\right|^{2}+\xi_{V}\left|V_{t}-V_{r e f}\right|^{2}\right) \mathrm{d} t
$$

Using such equation the voltage and frequency remain unchanged around their reference values, if by adjusting $\xi_{\omega}, \xi_{V}$ the frequency and voltage regulation could be changed by providing such facility in the controller [8]. The power balance in terminal bus should be considered with system constraints as below:

$$
P_{G}=P_{\text {Consumed }}-P_{i}
$$

The control action and related constraints for optimal power flow should be taken into account w.r.t. to minimum to maximum generating capacity of source. [11].

\section{Simulation Results for Optimal Power Flow}

The simulation is based on power block diagram and equations related to it, the results are represented for its respective capacity of source which caters to power delivered by each source of the network [12]. The electricity generation by each source is for expected output of it, which will satisfy the load. The capacity of each is as specified below with variation in the load from 100 watt to 500 watt. 


\begin{tabular}{cccc}
\hline Solar PV & Wind Energy & Diesel Generator & Battery \\
\hline 500 watt, 70 Volt & 200 watt, 230 Volt & $5 \mathrm{KVA}$ & $12 \mathrm{~V}, 100 \mathrm{AH}$ \\
\hline
\end{tabular}

For optimal power analysis the simulation model is simulated with specified parameters, for $P_{D}(t) \geq P_{i}(t)$ and $P_{D}(t) \leq P_{i}(t)$, the results gives satisfactory operation of all sources as shown in Figure 5, which represents contribution of each source with variation in load as per their electricity generation strategy [5].

\section{Distributed Generation (DG) Optimization Method}

As seen from Figure 2 the process of optimization is carried out in following steps for both ON and OFF control of system:

a) Data and input parameters are specified which they include electricity generation, the load curve, the percentage of loads and the ecological characteristics of the site.

b) DG and switching ON/OFF of sources is as per consumption of power by loads datasheet.

c) Initial values for the capacity of DGs and loads are randomly identified based on optimal power flow.

d) Optimal instantaneous power flow, based on utilization over the entire process of the system, is determined by as load follows. Given the capacity for each DG, determined from the previous step, economic-environmental dispatch can be calculated by minimizing the power. Next, the power available from RES is determined based on (1) and (2) and the remaining required power is generated by other DGs and grid according the economic environmental dispatch.

At the same time, as a source during peak times and is subject to deliver the power. During off-peak hours as a load and its duration.

e) Given the capacity for each DG, as determined from the third step, power flow optimizes and switching ON/OFF based on reliability therefore, consumer outage are minimized.

f) Given the power generated by each unit, determined from the previous step of each source.

g) Using the capacity of each DG, as determined by power flow optimization. Using obtained optimum capacities, the type and size of the sources, forming Micro Grid's, are identified.

Also, Operational Strategy is determined on an hour-by-hour basis, using steps 4 - 7 .

\section{Results}

The optimal power flow for its power flow analysis with each source of generation of electricity is deployed for hardware implementation based on available Solar PV (500 W, $100 \mathrm{~V})$, Wind energy $(200 \mathrm{~W}, 230 \mathrm{~V})$ and battery $12 \mathrm{~V}, 100$ $\mathrm{AH}$ with existing grid of $230 \mathrm{~V}$ for nonlinear or variable loads shown in Figure 6. 


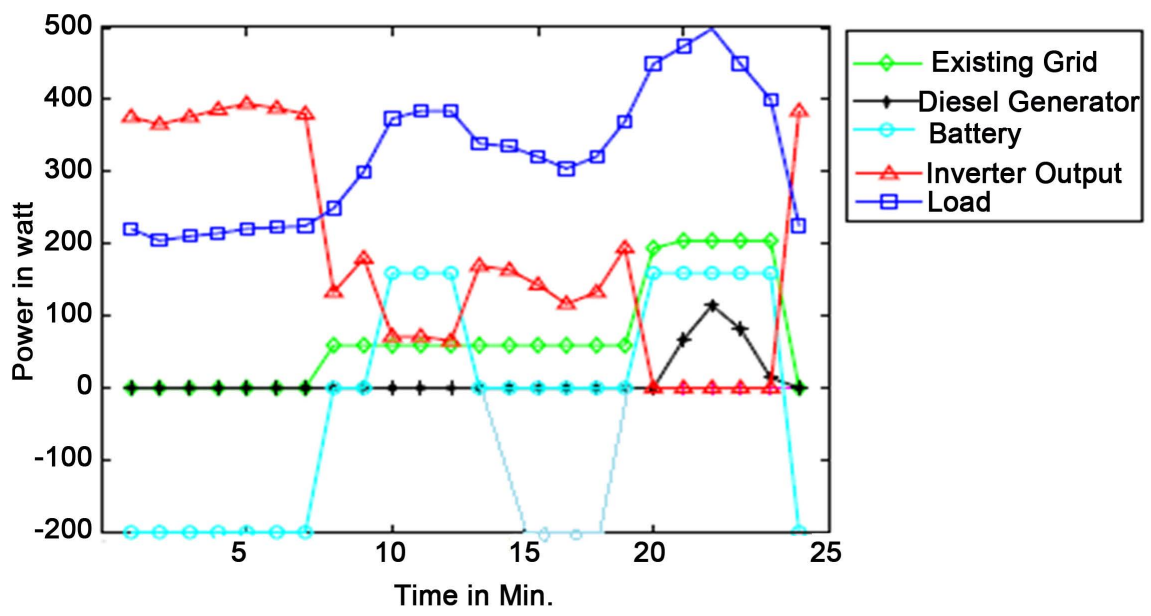

Figure 5. Optimal power flow analysis of simulation model for power system.

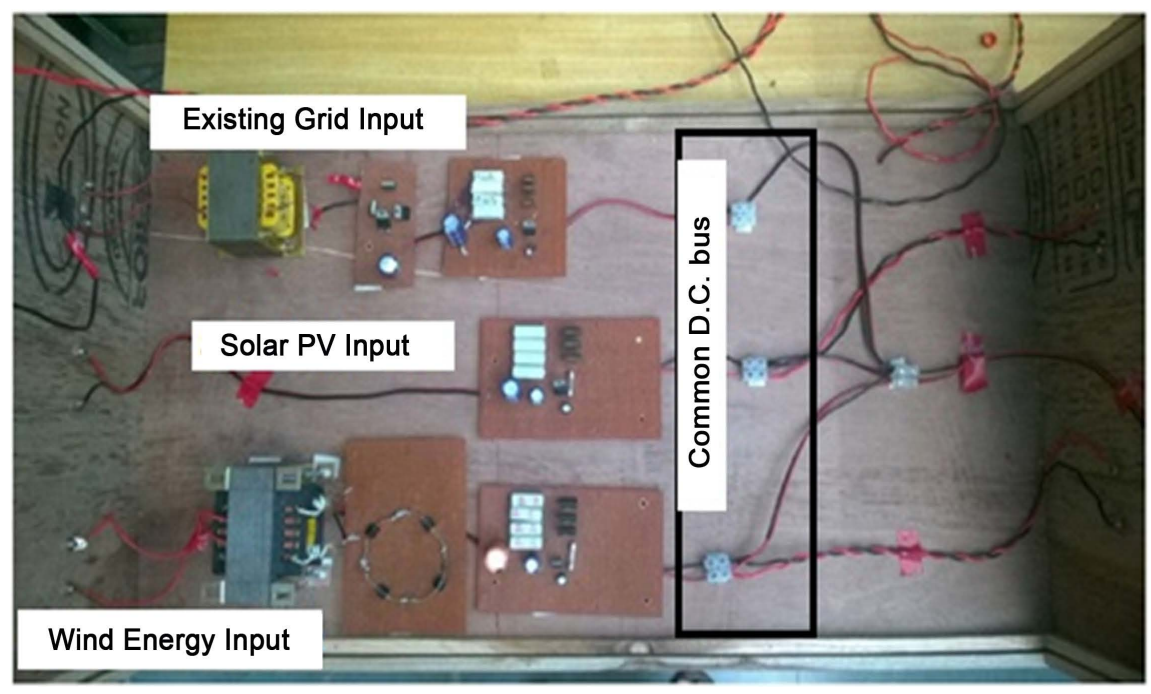

Figure 6. Power flow model of solar PV, wind energy and existing grid.

Each source is synchronised manually with existing grid for the parameters like voltage, frequency and waveform by power analyser and same is reported.

The proposed hardware consists of integration of distributed generation such as solar PV, wind energy system, battery with the conventional grid. From the various topologies available for integration, the common DC bus topology is selected and a common DC bus of 96 volt is formed. Figure 6 shows the interconnection of various equipment in the hardware setup. At the output of d. c. bus a single phase inverter connected which gives the supply to non-linear load.

\section{Results and Discussion}

From Figure 4 the simulation results for the system in Figure 5 have been obtained the same have explored for a small capacity system consisting of Solar PV, Wind Energy, Battery, Diesel Generator and Existing Grid of total capacity 1 KW. The results shown in Figures 7-10 with following sources are seen consistent with simulation results at Figure 5. 


\begin{tabular}{ccc}
\hline Sr. No. & Source & Capacity \\
\hline 1 & Solar PV & 500 watt, 70 Volt \\
2 & Wind Energy & 200 watt, 230 Volt \\
3 & Battery & $12 \mathrm{~V}, 100 \mathrm{AH}$ \\
4 & Existing Grid & $230 \mathrm{~V}, 1 \mathrm{KW}$ \\
\hline
\end{tabular}

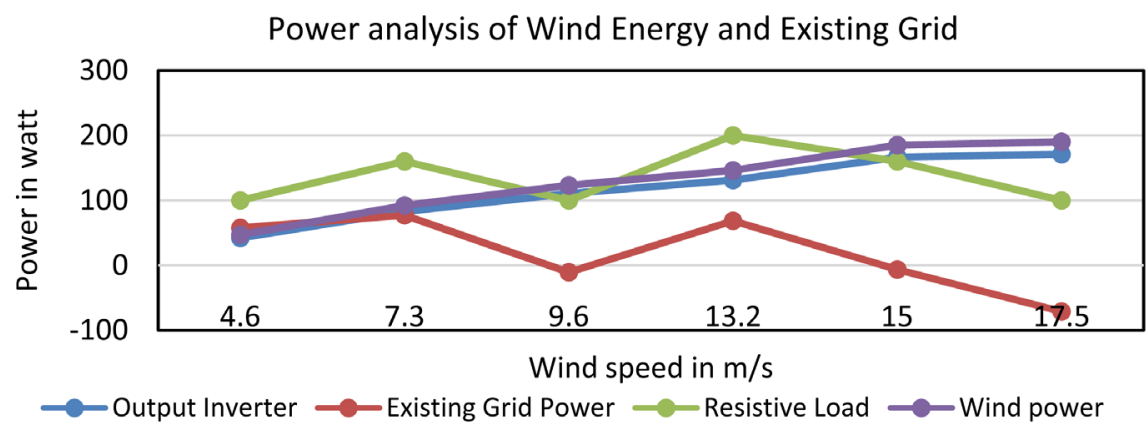

Figure 7. Power flow analysis of wind energy. (Synchronizing parameters at the instant of switching with grid $f=49.7 \mathrm{~Hz}, V=217.5$ volt, identical waveform).

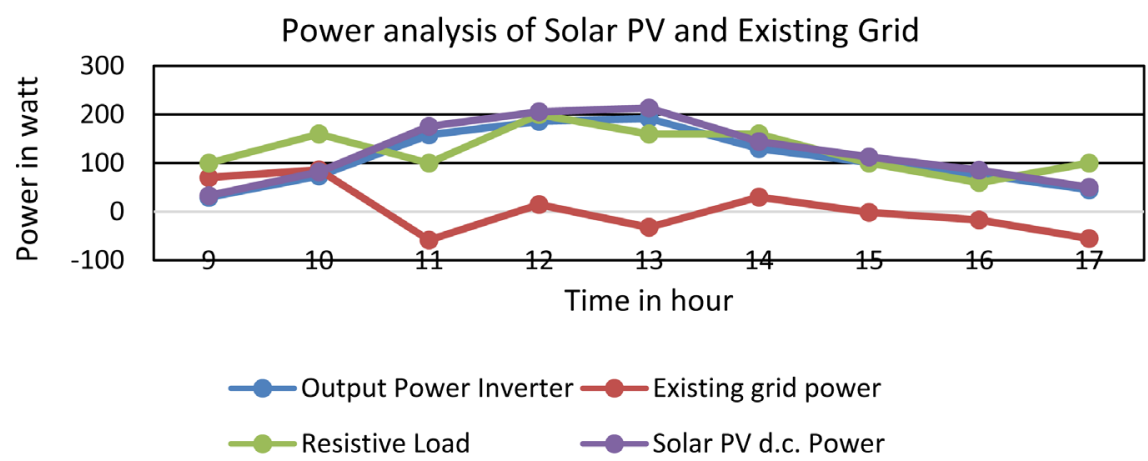

Figure 8. Power flow analysis of Solar PV. (Synchronizing parameters at the instant of switching with grid $f=49.9 \mathrm{~Hz}, V=220.7$ volt, identical waveform).

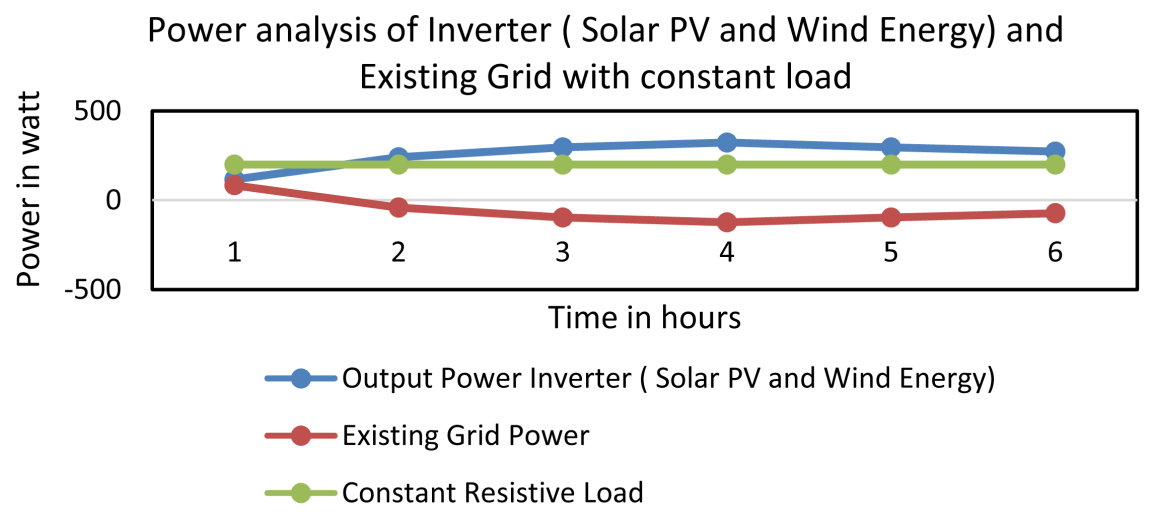

Figure 9. Power flow analysis with constant load. (Synchronizing parameters at the instant of switching with grid $f=50 \mathrm{~Hz}, V=219.5$ volt, identical waveform).

The results in Figures 7-10 are obtained for real time pilot system in the laboratory, which clearly depict the effectiveness of RES with conventional grid leading to so called Smart Grid concept. 


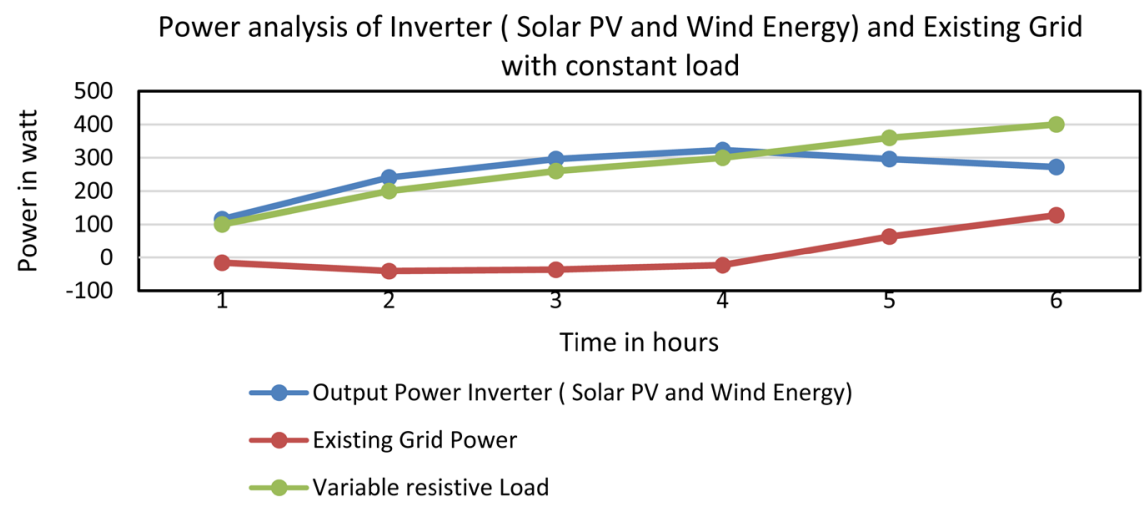

Figure 10. Power flow analysis with variable load. (Synchronizing parameters at the instant of switching with grid $f=49.9 \mathrm{~Hz}, V=225.4$ volt, identical waveform).

\section{Conclusion}

The adaptive power management to uncertain RES generation in single-feeder distribution networks was formulated as a power flow optimization. From Figure 5, Figures 7-10 the simulation and hardware results are consistent. It includes real power consumption for variable loads with respect to synchronising the RES and existing grid parameters at PCC. An optimal power flow solution was developed based on the RES generation sources leading to closed-form updates per node and per scenario. Tests were conducted on distribution networks with Solar PV, Wind Energy and existing grid by using a scenarios to illustrate the effectiveness of the formulation. The superior performance of the proposed system was also highlighted through comparisons with an individual generation scheme in terms of synchronising the voltage, frequency and waveform of these generation sources with manual mode of operation. In future it is entitled to develop an AUTO operation system for the same as Smart grid.

\section{References}

[1] Bolognaise, S., Cavraro, G., Cerruti, F. and Costabeber, A. (2011) A Linear Dynamic Model for Micro Grid Voltages in Presence of Distributed Generation. 2011 IEEE First International Workshop on Smart Grid Modeling, Simulation (SGMS), at IEEE SmartGridComm, 31-36.

[2] Balenciaga, F. and Puleston, P.F. (2005) Supervisor Control for a Stand-Alone Hybrid Generation System Using Wind and Photovoltaic Energy. IEEE Transaction Energy Conversion, 20, 398-405.

[3] Jafari, H., Mahmodi, M. and Rastegar, H. (2012) Frequency Control of Micro-Grid in Autonoums Mode Using Predictive Control. 2nd Iranian IEEE Conference on Smart Grid, 1, 231-236.

[4] Logenthiran, T., Srinivasan, D. and Shun, T.Z. (2012) Demand Side Management in Smart Grid Using Heuristic Optimization. IEEE Transactions on Smart Grid, 3, 1244-1252.

[5] Erseghe, T. (2014) A Distributed Algorithm for Fast Optimal Power Flow Regulation in Smart Grids. 2014 IEEE International Conference on Smart Grid Communications, 31-36.

[6] Bugade, V.S. and Katti, P.K. (2015) Dynamic Modelling of Micro grid with Distrib- 
uted Generation for Grid Integration. 2015 IEEE International Conference on Energy Systems and Applications (ICESA 2015), 30 October-1 November 2015, 102-106.

[7] Chen, Y.-M., et al. (2007) Multi-Input Inverter for Grid-Connected Hybrid PV/Wind Power System. IEEE Transactions on Power Electronics, 22, 1070-1077.

[8] Shabestary, S.M.A., Saeedmanesh, M., Rahimi-Kian, A. and Jalalabadi, E. (2012) Real Time Frequency and Voltage Control of Islanded Micro Grid. 2nd Iranian IEEE conference on Smart Grid, 1, 310-315.

[9] Liu, Y., Zhang, Y., Chen, K.R., Chen, S.Z. and Tang, B. (2016) Equivalence of Multi-Time Scale Optimization for Home Energy Management Considering User Discomfort Preference. IEEE Transactions on Smart Grid, 1, 1-12.

[10] Wu, D., Tang, F., Dragicevic, T., Vasquez, J.C. and Guerrero, J.M. (2015) A Control Architecture to Coordinate Renewable Energy Sources and Energy Storage Systems in Islanded Micro Grids. IEEE Transactions on Smart Grid, 6, 1156-1166.

[11] Makhe, A., Bugade, V.S., Matkar, S. and Mothe, P. Digital Protection of LVDC and Integration of Distributed Generation. IEEE International Conference on Energy Efficient Technologies for Sustainability (ICEETS 16).

[12] Liu, B.Q., Zhou, F., Zhu, Y.X. and Yi, H. (2015) System Operation and Energy Management of a Renewable Energy-Based DC Micro-Grid for High Penetration Depth Application. IEEE Transactions on Smart Grid, 6, 1147-1155.

\section{Nomenclature:}

$P_{D}$ - Load demand Power

$P_{i}$-Inverter Output Power

$P_{G}$-Existing Grid Power

$P_{d g}$-Diesel Generator Power

$P_{s p v}$-Solar PV Power

$P_{\text {we }}$-Wind Energy Power

$P_{b}$ - Battery Power

$U_{p}-$ Active power output signal from inverter

$U_{q}$-Reactive power output signal from inverter

$\xi_{\omega}$-Coefficient of frequency regulation

$\xi_{V}-$ Coefficient of voltage regulation 
Submit or recommend next manuscript to SCIRP and we will provide best service for you:

Accepting pre-submission inquiries through Email, Facebook, LinkedIn, Twitter, etc. A wide selection of journals (inclusive of 9 subjects, more than 200 journals)

Providing 24-hour high-quality service

User-friendly online submission system

Fair and swift peer-review system

Efficient typesetting and proofreading procedure

Display of the result of downloads and visits, as well as the number of cited articles Maximum dissemination of your research work

Submit your manuscript at: http://papersubmission.scirp.org/

Or contact sgre@scirp.org 